Marquette University

e-Publications@Marquette

School of Dentistry Faculty Research and

Publications

Dentistry, School of

$2-22-2020$

\title{
A Ferrofluidic Hydrophobic Deep Eutectic Solvent for the Extraction of Doxycycline from Urine, Blood Plasma and Milk Samples Prior to its Determination by High-Performance Liquid Chromatography-Ultraviolet
}

\author{
Ebrahim Alipanahpour Dil \\ Yasouj University \\ Mehrorang Ghaedi \\ Yasouj University \\ Arash Asafram \\ Yasuj University of Medical Sciences \\ Lobat Tayebi \\ Marquette University, lobat.tayebi@marquette.edu \\ Fatemah Mehrabi \\ Yasouj University
}

Follow this and additional works at: https://epublications.marquette.edu/dentistry_fac

Part of the Dentistry Commons

\section{Recommended Citation}

Alipanahpour Dil, Ebrahim; Ghaedi, Mehrorang; Asafram, Arash; Tayebi, Lobat; and Mehrabi, Fatemah, "A Ferrofluidic Hydrophobic Deep Eutectic Solvent for the Extraction of Doxycycline from Urine, Blood Plasma and Milk Samples Prior to its Determination by High-Performance Liquid ChromatographyUltraviolet" (2020). School of Dentistry Faculty Research and Publications. 402.

https://epublications.marquette.edu/dentistry_fac/402 
Marquette University

e-Publications@Marquette

\section{School of Dentistry Faculty Research and Publications/School of Dentistry}

This paper is NOT THE PUBLISHED VERSION.

Access the published version via the link in the citation below.

Journal of Chromatography A, Vol. 1613, (February 22, 2020): 460695. DOI. This article is (C) Elsevier and permission has been granted for this version to appear in e-Publications@Marquette. Elsevier does not grant permission for this article to be further copied/distributed or hosted elsewhere without the express permission from Elsevier.

\section{A Ferrofluidic Hydrophobic Deep Eutectic Solvent for the Extraction of Doxycycline from Urine, Blood Plasma and Milk Samples Prior to its Determination by High-Performance Liquid Chromatography-Ultraviolet}

Ebrahim Alipanahpour Dil

Department of Chemistry, Yasouj University, Yasouj, Iran

Mehrorang Ghaedi

Department of Chemistry, Yasouj University, Yasouj, Iran

Arash Asafram

Medicinal Plants Research Center, Yasuj University of Medical Sciences, Yasuj, Iran

Lobat Tayebi

Marquette University School of Dentistry, Milwaukee, WI, USA

Fatemeh Mehrabi

Department of Chemistry, Yasouj University, Yasouj, Iran 


\section{Abstract}

The ferrofluid phase was prepared according to mixing magnetic nanoparticle and the hydrophobic deep eutectic solvent as a green microextraction solvent. This new composite was applied for vortex-assisted dispersive liquid-liquid microextraction (VA-HDES-ferrofluid-DLLME) of doxycycline (DOC) residual extraction and determined through high-performance liquid chromatography-ultraviolet (HPLC-UV). The characterization of magnetic nanoparticle was investigated by XRD, TEM and FESEM. The dependency of DOC microextraction to main variables and their interaction and find optimum points were undertaken using response surface methodology with either central composite design (CCD). Thus, the optimum $\mathrm{pH}$, ionic strength, ferrofluid volume and vortex time for DOC extraction are determined to be $3.0,4 \% \mathrm{w} / \mathrm{v}, 150 \mu \mathrm{L}$ and $7 \mathrm{~min}$, respectively. According to this condition, linear response is found to be greater than $10-400 \mathrm{ng} \mathrm{mL}^{-1}$, with a correlation coefficient of 0.983 . The detection and quantification limits are 3.6 and $8.5 \mathrm{ng} \mathrm{mL}^{-1}$, while the repeatability and reproducibility as precision criteria (RSD\%) are $3.74 \%$ and $4.15 \%$, respectively. The DOC recoveries in all of the urine, blood plasma and milk samples are between 86.70 and $97.48 \%$, with RSD\% lower than 5.72\%.

\section{Keywords}

Doxycycline, Ferrofluid, High-performance liquid chromatography (HPLC), Hydrophobic deep eutectic solvent, Vortex-assisted dispersive liquid-liquid microextraction

\section{Introduction}

Doxycycline (DOC) belongs to the tetracycline antibiotic family and has extensive application in human life [1]. DOC is classified as a member of tetracycline, containing $\beta$-diketonate structure. It has comprehensive range of antibacterial roles and is recommended for the action of particular contagions because of its impartially dependable absorption and extended half-life-and accordingly, its need for fewer administrations. It is often used to treat pelvic inflammatory disease, chlamydia, syphilis and sinusitis [2]. The monitoring of DOC in biological samples is meaningful owing to high levels of DOC, which leads to bacterial resistance and serious health problems including yellowing of teeth, allergic reactions, damage to the liver and gastrointestinal upset $[3,4]$.

Measurement of DOC in biological samples usually includes extraction, clean-up technique and instrumental analysis [5]. However, the use of advanced devices for the analysis of DOC would allow urgent highly effective sample preparation requirements to design and develop an approach to quantify this compound in complex samples with content lower than their LOD. The most typical protocol for the DOC separation and/or preconcentration from biological samples contains dispersive solid-phase microextraction (DSPME), dispersive liquid-liquid microextraction (DLLME) [6], liquid-liquid extraction (LLE), solid-phase extraction (SPE), matrix solid-phase dispersion (MSPD) or QuEChERS (which is quick, easy, cheap, effective, rugged and safe) [7].

The improvement of a novel microextraction based sample preparation would provide a rapid, simple and effective strategy, as it uses the smallest volume of organic solvents and sorbent [8]. DLLME is an ecofriendly microextraction procedure that permits effective, rapid and simple analysis without the requirement of special instruments $[9,10]$.

The extracting solvent can be separated and decanted simply from the solid phase via jointing and combination magnetic nanomaterial. The ferrofluid based on the mixture of magnetic nanomaterial with a carrier agent helped to overcome some disadvantages in recovering extractor [11]. Ferrofluid application, as an extractor liquid, is associated with resolving or reducing special equipment, refrigeration and centrifugation. Ferrofluids 
are composed of stable colloidal magnetic nanomaterial suspended in a carrier solvent. The magnetic nanomaterial in carrier solvent helps with the accumulation of species because of its dipolar attractive interactions, Van der Waals forces, magnetostatic interactions and more $[12,13]$. Such innovation in lower scale extractions leads to more rapid phase disengagement rate, with respect to the customary process $[14,15]$.

A better presentation of the microextraction process is achieved by using a mathematical method to obtain a more refined knowledge of the process and supply more exact outcomes [16]. Accordingly, the correlation among different factors and response were revealed and modeled, which consequently optimal conditions is suggested and predicted [17].

The aim of present research is the synthesis of the ferrofluid based on magnetic nanoparticles and hydrophobic deep eutectic solvent, along with its subsequent usage for extraction of DOC based on VA-HDESferrofluid-DLLME method. The individual and interactive effect of factors on the microextraction of DOCincluding ferrofluid volume, $\mathrm{pH}$, vortex time and ionic strength ( $\mathrm{NaCl}$ concentration $(\% \mathrm{w} / \mathrm{v}))$ - is examined via CCD. Subsequently, DOC quantification is completed through combination of HPLC-UV with preliminary VAHDES-ferrofluid-DLLME in biological samples.

\section{Experimental}

\subsection{Reagents and instruments}

All reagents-such as $\mathrm{FeCl}_{3} \bullet 6 \mathrm{H}_{2} \mathrm{O}(\geq 99 \%), \mathrm{FeCl}_{2} \bullet 4 \mathrm{H}_{2} \mathrm{O}(\geq 99.0 \%), \mathrm{NH}_{4} \mathrm{OH}\left(30 \%-33 \% \mathrm{NH}_{3}\right.$ in $\mathrm{H}_{2} \mathrm{O}$ ), acetone ( $\left.\geq 99.9 \%\right)$, methanol $(\geq 99.9 \%)$, acetonitrile (99.8\%) octanoic acid ( $\left.\geq 98 \%\right)$, doxycycline (DOC; $\geq 98 \%)$, DL-menthol (99\%), oleic acid ( $\geq 99 \%), \mathrm{NaOH}(\geq 98 \%)$ and $\mathrm{HCl}(37 \%)$-were purchased from Merck, Darmstadt, Germany. Ultrapure water was prepared from a MilliQ gradient water purification system. The $\mathrm{pH}$ values of all solutions were controlled with a pH/Ion meter (model-686, Metrohm, Switzerland, Swiss). The morphology and average size of the $\mathrm{Fe}_{3} \mathrm{O}_{4}$ nanoparticles were examined by field emission scanning electron microscopy (FE-SEM: ZEISS, Sigma VP Germany) and transmission electron microscope (TEM, Zeiss model EM 10C, Germany). X-ray diffraction (XRD) pattern was achieved with an automated Philips X'Pert X-ray diffractometer (Philips, Netherland). A vortex agitation system (Retsch, Germany) was utilized to quicken the extraction. An ultrasonic bath (Tecno-GAZ SPA Ultra Sonic System, Italy) at ambient temperature, frequency and power of $40 \mathrm{kHz}$ and $130 \mathrm{~W}$, respectively, was used to disperse the $\mathrm{Fe}_{3} \mathrm{O}_{4}$ nanoparticles in deep eutectic solvent [18], [19], [20].

HPLC analysis was obtained by an Agilent 1100 liquid chromatography (Wilmington, DE, USA) that contained a micro vacuum degasser (model G1379A), quaternary pump (model G1311A), multiple wavelength detector (model G13658), sample injection valve with a $20 \mu \mathrm{L}$ sample loop and an Agilent C18 column (4.6 mm i.d. $250 \mathrm{~mm}, 5 \mu \mathrm{m})$. Acetonitrile (25\%) and water (75\% v/v) adjusted to $\mathrm{pH} 2.5$ with orthophosphoric acid were used as the mobile phase in this analysis. All the measurement operations were carried out at ambient temperature, followed by ultraviolet detector wavelength was operated at $245 \mathrm{~nm}$ for the analyte (DOC). STATISTICA software version 10.0 (Stat Soft Inc., Tulsa USA) was utilized for the design of experiments, model fitting and DOC extraction efficiency significance.

\subsection{Synthesis of Iron Oxide (Fe3O4) nanoparticles coated with oleic acid}

An aqueous solution ( $150 \mathrm{~mL}$ distilled water) of $\mathrm{FeCl}_{3} \bullet 6 \mathrm{H}_{2} \mathrm{O}\left(1.1 \mathrm{~g}\right.$ ) and $\mathrm{FeCl}_{2} \bullet 4 \mathrm{H}_{2} \mathrm{O}(0.4 \mathrm{~g})$-in the $\mathrm{Fe}$ (III): $\mathrm{Fe}$ (II) molar ratio $2: 1-$ was kept at $60^{\circ} \mathrm{C}$ for 15 min under vigorous stirring. Next, ammonium hydroxide solution $\left(20 \mathrm{~mL} \mathrm{NH}_{4} \mathrm{OH}(25 \%)\right)$, under the previously mentioned conditions, was added until the $\mathrm{pH}$ reached $\sim 11$, which lead to formation of a black suspension that was subsequently stirred at $50^{\circ} \mathrm{C}$ for $2 \mathrm{~h}$ with $\mathrm{N}_{2}$ gas.

$\mathrm{Fe}_{3} \mathrm{O}_{4}$ nanoparticles were collected by an external magnet, washed with deionized water several times and dried overnight in a vacuum oven [21]. Then, $0.5 \mathrm{~g}$ of $\mathrm{Fe}_{3} \mathrm{O}_{4}$ nanoparticles were mixed thoroughly with $10 \% \mathrm{v} / \mathrm{v}$ oleic 
acid under vigorous stirring at $150 \mathrm{rpm}$ for $2 \mathrm{~h}$ [22]. Finally, the suspended particles were washed five times with $10 \mathrm{~mL}$ of an acetone-methanol mixture $(1: 1 \mathrm{v} / \mathrm{v})$ to remove the excess oleic acid. Last, the prepared suspension $\left(\mathrm{Fe}_{3} \mathrm{O}_{4}-\mathrm{OA}\right)$ was separated through magnetic decantation, followed by drying under a vacuum for $24 \mathrm{~h}$ [23].

\subsection{Preparation of hydrophobic deep eutectic solvent}

The hydrophobic deep eutectic solvent was prepared by mixing octanoic acid and DL-menthol with 1:1 molar

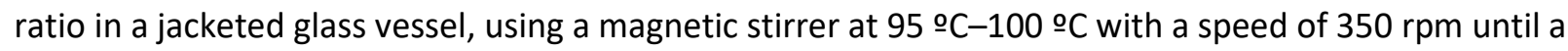
homogeneous liquid developed and no solid is observed. This liquid was then cooled down slowly until it reached room temperature.

\subsection{Preparation of ferrofluid}

$50 \mathrm{mg}$ of $\mathrm{Fe}_{3} \mathrm{O}_{4}-\mathrm{NP}$ coated with oleic acid, as a magnetic nanomaterial, was diffused in $1 \mathrm{~mL}$ of DES. The mixture was then sonicated for about $20 \mathrm{~min}$, leading to formation of stable ferrofluid. This was subsequently applied in the next stage for the VA-HDES-ferrofluid-DLLME procedure.

\subsection{Vortex-assisted dispersive liquid-liquid microextraction procedure}

A $10 \mathrm{~mL}$ of DOC solution $\left(150 \mathrm{ng} \mathrm{mL}^{-1}\right)$, with a pH 3.0 and in the presence of $4 \mathrm{w} / \mathrm{v} \%$ of $\mathrm{NaCl}$ was added to a $15 \mathrm{~mL}$ centrifuge tube. Next, $150 \mu \mathrm{L}$ ferrofluid was added, then the mixture was vigorously shaken by a vortex agitator for $7 \mathrm{~min}$. Afterward, a strong magnet was placed near the centrifuge tube in order to attract and isolate the extraction solvents. Finally, the sample solution was discarded through decanting. After removal of the magnet and introduction of $50 \mu \mathrm{L}$ methanol (as the precipitation reagent) into the vial, exposure to the magnet at the bottom of the centrifuge tube leads to phase separation. After setting magnetic nanoparticles, the extraction phase was collected into an Eppendorf tube and, consequently, $20 \mu \mathrm{L}$ was injected into HPLC for quantification and separation of DOC.

\subsection{Experimental design}

The STATISTICA, along with CCD, provides appropriate analysis of variance when given numerical estimation of main and interaction of variables-including pH (1.5-7.5), ferrofluid volume (50-250 $\mu \mathrm{L})$, ionic strength ( $\mathrm{NaCl}$ concentration $(1-5 \% \mathrm{w} / \mathrm{v})$ ) and vortex time (1-7 min)-based on conduction of 30 experiments (Table 1). Subsequently, 3D dimensional and predicted versus actual value plots demonstrate usefulness and tendencies of contribution of variables and their interaction on responses.

Table 1. Design matrix for the central composite designs.

\begin{tabular}{|c|c|c|c|c|c|c|c|}
\hline \multicolumn{3}{|c|}{ Factors } & \multicolumn{2}{|c|}{ Levels } & & & \\
\hline & & & $-\alpha$ & Low (-1) & Central (0) & High (+1) & $+\alpha$ \\
\hline \multicolumn{3}{|c|}{$\mathrm{A}: \mathrm{pH}$} & 1.5 & 3.0 & 4.5 & 6.0 & 7.5 \\
\hline \multicolumn{3}{|c|}{ B: $\mathrm{NaCl}$ concentration (\%w/v) } & 1 & 2 & 3 & 4 & 5 \\
\hline \multicolumn{3}{|c|}{ C: Ferrofluid volume $(\mu \mathrm{L})$} & \multirow{2}{*}{$\begin{array}{l}50 \\
1.0\end{array}$} & 100 & 150 & 200 & 250 \\
\hline \multicolumn{3}{|c|}{ D: Vortex time $(\mathrm{min})$} & & 2.5 & 4.0 & 5.5 & 7.0 \\
\hline Run & A & B & & $\mathrm{C}$ & $\begin{array}{l}\mathbf{D} \\
\end{array}$ & ER (\%) & \\
\hline 1 & 4.50 & 3.00 & & 150.00 & 4.00 & 96.454 & \\
\hline 2 & 3.00 & 2.00 & & 100.00 & 5.50 & 67.985 & \\
\hline 3 & 6.00 & 2.00 & & 200.00 & 5.50 & 71.661 & \\
\hline 4 & 7.50 & 3.00 & & 150.00 & 4.00 & 76.183 & \\
\hline 5 & 6.00 & 4.00 & & 100.00 & 2.50 & 78.669 & \\
\hline 6 & 6.00 & 2.00 & & 200.00 & 2.50 & 70.967 & \\
\hline 7 & 6.00 & 2.00 & & 100.00 & 5.50 & 67.019 & \\
\hline 8 & 4.50 & 3.00 & & 150.00 & 4.00 & 96.703 & \\
\hline
\end{tabular}




\begin{tabular}{|l|l|l|l|l|l|}
\hline 9 & 4.50 & 3.00 & 150.00 & 7.00 & 96.518 \\
\hline 10 & 4.50 & 3.00 & 150.00 & 4.00 & 97.381 \\
\hline 11 & 4.50 & 1.00 & 150.00 & 4.00 & 54.402 \\
\hline 12 & 6.00 & 4.00 & 200.00 & 5.50 & 80.769 \\
\hline 13 & 4.50 & 3.00 & 150.00 & 4.00 & 95.172 \\
\hline 14 & 3.00 & 4.00 & 200.00 & 2.50 & 84.371 \\
\hline 15 & 4.50 & 3.00 & 50.00 & 4.00 & 70.896 \\
\hline 16 & 4.50 & 3.00 & 150.00 & 4.00 & 95.502 \\
\hline 17 & 1.50 & 3.00 & 150.00 & 4.00 & 83.591 \\
\hline 18 & 4.50 & 5.00 & 150.00 & 1.00 & 67.469 \\
\hline 19 & 4.50 & 3.00 & 150.00 & 4.00 & 98.316 \\
\hline 20 & 4.50 & 3.00 & 150.00 & 4.00 & 97.545 \\
\hline 21 & 3.00 & 2.00 & 100.00 & 2.50 & 68.183 \\
\hline 22 & 6.00 & 2.00 & 100.00 & 2.50 & 71.438 \\
\hline 23 & 3.00 & 2.00 & 200.00 & 2.50 & 72.957 \\
\hline 24 & 6.00 & 4.00 & 200.00 & 2.50 & 75.245 \\
\hline 25 & 3.00 & 2.00 & 200.00 & 5.50 & 79.793 \\
\hline 26 & 6.00 & 4.00 & 100.00 & 5.50 & 83.285 \\
\hline 27 & 4.50 & 3.00 & 250.00 & 4.00 & 75.285 \\
\hline 28 & 3.00 & 4.00 & 100.00 & 5.50 & 93.622 \\
\hline 29 & 3.00 & 4.00 & 100.00 & 2.50 & 87.073 \\
\hline 30 & 3.00 & 4.00 & 200.00 & 5.50 & 91.211 \\
\hline
\end{tabular}

\section{Result and discussion}

\subsection{Characterization}

The $\mathrm{Fe}_{3} \mathrm{O}_{4}$ nanoparticle investigation with FE-SEM (Fig. 1a) reveals particles of similar size and spherical shape, while TEM evaluation (Fig. 1b) reveals the unified size of many nanoparticles within the size range of 10-30 nm. The XRD analysis of $\mathrm{Fe}_{3} \mathrm{O}_{4}$ is composed of peaks related to (Fig. 1C) intensities of its pure form without impurity. This material (Fig. 1C) has eight $X$-ray diffraction peaks appearing at $2 \theta=30.0^{\circ}, 35.6^{\circ}, 37.0^{\circ}, 43.1^{\circ}, 47.0^{\circ}, 53.4^{\circ}$,

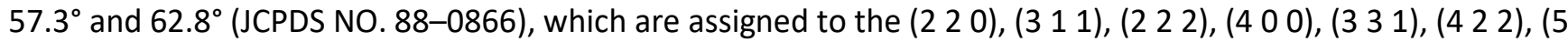
$11)$ and (4 40$)$ crystal planes, respectively. 


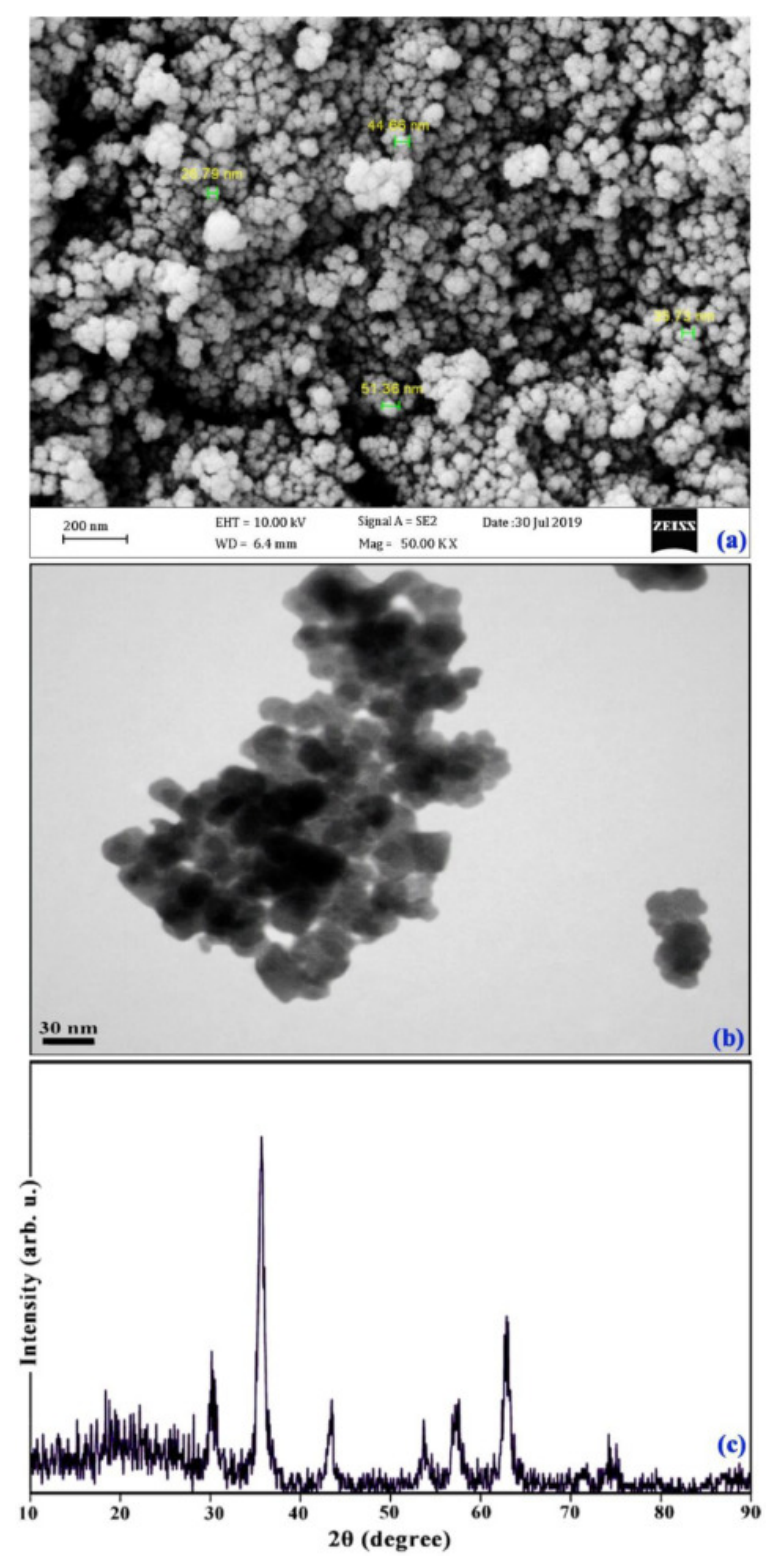

Fig. 1. (a) SEM image, (b) TEM image and (c) XRD pattern of the $\mathrm{Fe}_{3} \mathrm{O}_{4}$ nanoparticle.

\subsection{Experimental design and data analysis}

The CCD, as best optimization tools, was applied to investigate the correlation among variables, including ferrofluid volume, $\mathrm{pH}$, vortex time, ionic strength ( $\mathrm{NaCl}$ concentration $(\% \mathrm{w} / \mathrm{v}))$ and $\mathrm{DOC}$ extraction (response). Based on selected levels, according to Table 1, the recommended experimental factors were undertaken, and their consequent response is represented in Table 2. The interaction and main effects at $95 \%$ confidence level were estimated using ANOVA according to judgment based on F-test and their respective $p$ value. The obtained construct between the ER\% and independent factors (Eq. (1)) based on numerical value are mentioned as follows. The positive sign indicates synergistic effects, while the negative sign shows the antagonistic effects [24].

(1) 


$$
\begin{aligned}
\operatorname{ER}(\%)= & -121.52345+22.43710 \mathrm{~A}+59.62849 \mathrm{~B}+0.85833 \mathrm{C} \\
& +2.30473 \mathrm{D}-1.26983 \mathrm{~A}-0.011032 \mathrm{AC} \\
& -0.37811 \mathrm{AD}-0.039757 \mathrm{BC}+0.83145 \mathrm{BD} \\
& +0.011122 \mathrm{CD}-1.90597 \mathrm{~A}^{2}-7.46748 \mathrm{~B}^{2} \\
& -2.39502 \mathrm{E}-003 \mathrm{C}^{2}-0.45438 \mathrm{D}^{2}
\end{aligned}
$$

\begin{tabular}{|c|c|c|c|c|c|c|}
\hline Factor & Sums of squares & Df* & Mean squa & tares & $F$-value & $P$-value \\
\hline Model & 4220.86 & 14 & 301.49 & & 126.68 & $<0.0001$ \\
\hline A & 154.83 & 1 & 154.83 & & 65.05 & $<0.0001$ \\
\hline$B$ & 800.43 & 1 & 800.43 & & 336.32 & $<0.0001$ \\
\hline $\mathrm{C}$ & 14.23 & 1 & 14.23 & & 5.98 & 0.0273 \\
\hline D & 54.99 & 1 & 54.99 & & 23.10 & 0.0002 \\
\hline$A B$ & 58.05 & 1 & 58.05 & & 24.39 & 0.0002 \\
\hline$A C$ & 10.95 & 1 & 10.95 & & 4.60 & 0.0487 \\
\hline$A D$ & 11.58 & 1 & 11.58 & & 4.87 & 0.0434 \\
\hline $\mathrm{BC}$ & 63.23 & 1 & 63.23 & & 26.57 & 0.0001 \\
\hline $\mathrm{BD}$ & 32.81 & 1 & 32.81 & & 13.78 & 0.0021 \\
\hline$C D$ & 11.13 & 1 & 11.13 & & 4.68 & 0.0471 \\
\hline$A^{2}$ & 508.60 & 1 & 508.60 & & 213.70 & $<0.0001$ \\
\hline $\mathrm{B}^{2}$ & 1005.36 & 1 & 1005.36 & & 422.42 & $<0.0001$ \\
\hline$C^{2}$ & 991.48 & 1 & 991.48 & & 416.59 & $<0.0001$ \\
\hline$D^{2}$ & 18.84 & 1 & 18.84 & & 7.92 & 0.0131 \\
\hline Residual & 35.70 & 15 & 2.38 & & & \\
\hline Lack of Fit & 28.08 & 9 & 3.12 & & 2.46 & 0.1429 \\
\hline Pure Error & 7.62 & 6 & 1.27 & & & \\
\hline Cor Total & 4256.56 & 29 & & & & \\
\hline \multicolumn{7}{|c|}{ Model Summary Statistics } \\
\hline \multicolumn{2}{|c|}{ Std. Dev. } & \multicolumn{2}{|c|}{1.54} & \multicolumn{2}{|c|}{ R-Squared } & 0.9916 \\
\hline \multicolumn{2}{|l|}{ Mean } & \multicolumn{2}{|c|}{81.52} & \multicolumn{2}{|c|}{ Adj-R-Squared } & 0.9838 \\
\hline \multicolumn{2}{|l|}{ C.V.\% } & \multicolumn{2}{|c|}{1.89} & \multicolumn{2}{|c|}{ Pred-R-Squared } & 0.9565 \\
\hline \multicolumn{2}{|l|}{ PRESS } & \multicolumn{2}{|c|}{185.32} & \multicolumn{2}{|c|}{ Adeq-Precision } & 39.247 \\
\hline
\end{tabular}

Table 2. Analysis of variance (ANOVA) for determination of DOC.

$*$ Degrees of freedom.

The acceptability of a model is based on ANOVA (Table 2), and the respective results imply the model $F$-value was 126.68 . The corresponding $p$-value was $<0.0001$, and both of these values confirm its suitability for well representation of data. The model was evaluated by its coefficient of determination $\left(R^{2}\right)(0.9916) ; R^{2}$ was adjusted and predicted with value of 0.9838 and 0.9565 , respectively. The value of $R^{2}$ indicates that $99.16 \%$ of the response change is attributed to parameters effect. Fig. 2a shows acceptable and good agreement among experimental recoveries. The significant variables investigation by Pareto plat (Fig. $2 \mathrm{~b}$ ) represents and emphasizes the significant parameters exceeding the vertical line $(P=0.05)$ [25]. The low value of coefficient of variance (CV) (1.89\%) shows the precision of the proposed model and confirms its high reliability and applicability for fitting experimental results. Adequate precision measured the signal to noise ratio and ratio (39.247), which confirms adequate signal. 

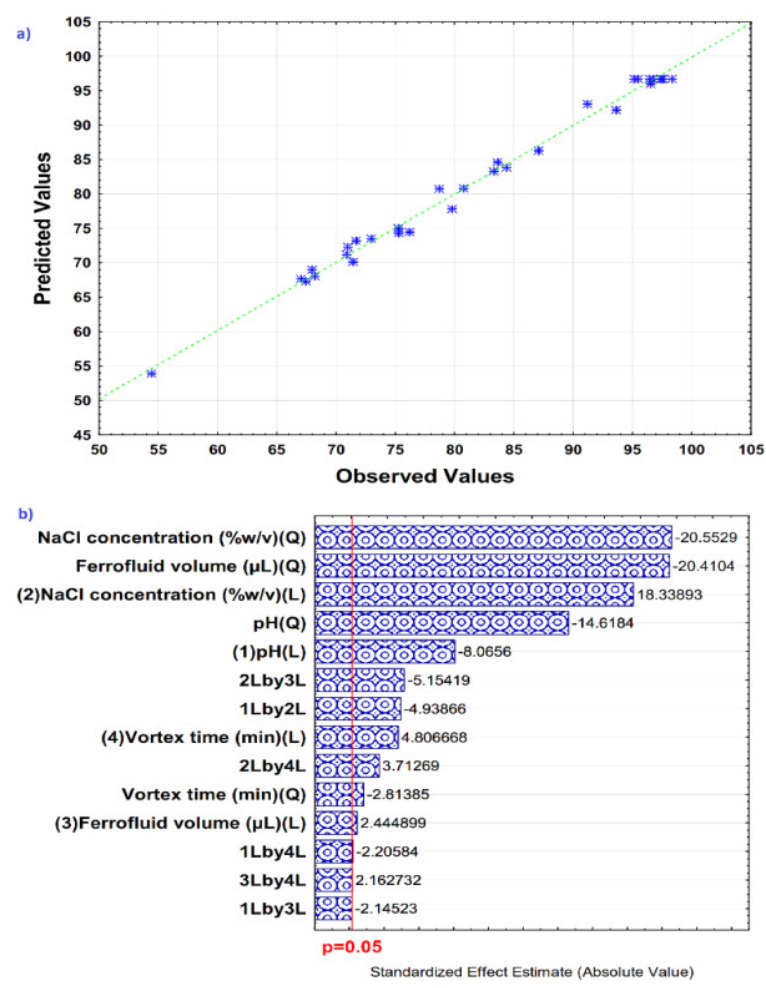

Fig. 2. (a) Correlation of experimental and predicted values, (b) Pareto chart for determination of DOC.

\subsection{D-dimensional plots}

Fig. 3 indicates the effects of all parameters on the extraction percentage, and as expected, DOC mass transfer and its respective mechanism strongly depend on solution $\mathrm{pH}$. The solution $\mathrm{pH}$ control at suitable $\mathrm{pH}$ suppresses the ionization of acidic or basic DOC species. Meanwhile, $\mathrm{pK}_{\mathrm{a}}$ of DOC $\left(\mathrm{pK}_{\mathrm{a}}=3.09\right)$ at high $\mathrm{pH}$ causes higher ionization, and basic compounds interfere with DOC extraction by the ferrofluid phase, which encourages us to investigate $\mathrm{pH}$ contribution in the range of 1.5-7.5. The optimal extraction efficiency was achieved at $\mathrm{pH}$ 3.0, and it was demonstrated that increasing or decreasing the $\mathrm{pH}$ decreases the extraction percentage. 
a)

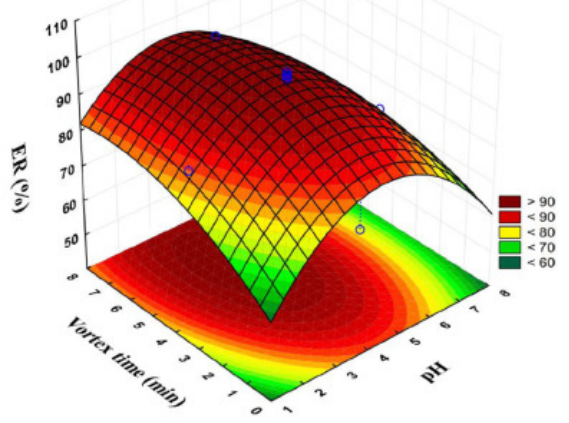

b)

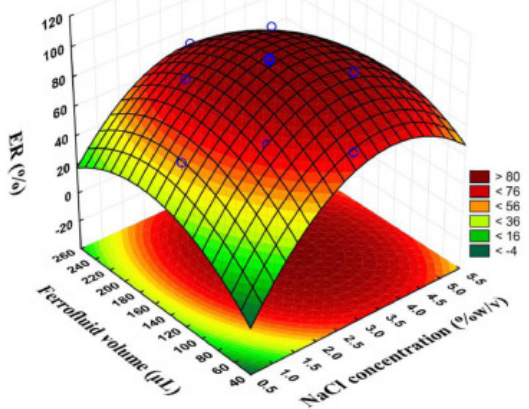

Fig. 3. Three-dimensional plot for determination of DOC.

Vortex time is an effective factor on extraction, as raising its respective time from 1 to 7 min leads to higher DOC extraction due to more intense binding interfaces of the ferrofluid phase and aqueous phase, which consequently improves and facilitate the migration and penetration of DOC molecules. The DOC extraction efficiency is improved at higher ferrofluid volume (Fig. 3a) up to $150 \mu \mathrm{L}$, and higher volume leads to sharp decrease in extraction percentage, which is attributed to the DOC dilution effect. Moreover, the ionic strength affects the DOC solubility in the aqueous phase, and accordingly, $\mathrm{NaCl}$ content contribution on the DOC extraction in the range of $1-5 \mathrm{w} / \mathrm{v} \%$ examination (Fig. $3 \mathrm{~b}$ ) indicates that its raising from 1 to $4 \mathrm{w} / \mathrm{v} \%$ leads increase of the extraction efficiency. Further increase (above $4 \% \mathrm{w} / \mathrm{v}$ ) causes a rise in solution viscosity, making mass transfer difficult and resulting in lower extraction efficiency.

\subsection{Optimization}

Fig. 4 shows the suggested optimum value of each factor on DOC extraction by CCD, which accordingly is set as $\mathrm{pH}$ of $3,150 \mu \mathrm{L}$ of ferrofluid, $4 \% \mathrm{w} / \mathrm{v} \mathrm{NaCl}$ and vortex time $7 \mathrm{~min}$, resulting in $99.36 \%$ extraction efficiency. 


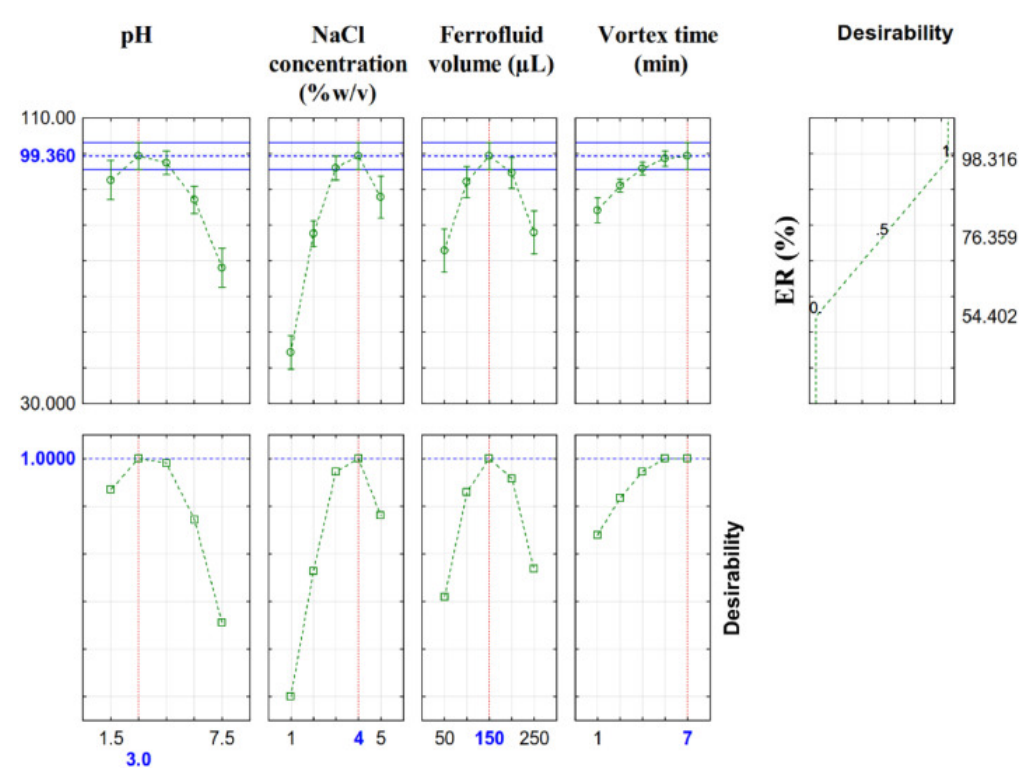

Fig. 4. Optimization plot for the determination of DOC.

\subsection{Method validation}

Analytical performance of the present ferrofluid liquid-phase microextraction method was investigated under optimum conditions $-\mathrm{pH}$ of $3,150 \mu \mathrm{L}$ of ferrofluid volume, ionic strength $(\mathrm{NaCl}$ concentration $(\% \mathrm{w} / \mathrm{v})$ ) of $4 \% \mathrm{w} / \mathrm{v}$ and $7 \mathrm{~min}$ vortex time (Table 3). The calibration graph was achieved after pre-concentration of standard DOC solutions between 10 and $400 \mathrm{ng} \mathrm{mL}^{-1}$ with $R^{2}$ of 0.983 . The enrichment factor, based on the calibration slope ratio after to before pre-concentration [26], is 83.61. The suitable closeness of pre-concentration factor (66.67) to enrichment factor confirms DOC quantitative extraction and recovery. The detection and quantification limits based on $3 \mathrm{~S}_{\mathrm{b}}$ and $10 \mathrm{~S}_{\mathrm{b}}$ division to calibration curve slope, while $S_{b}$ represents the blank standard deviation $(n=10)[27,28]$ were $3.6 \mathrm{ng} \mathrm{mL}^{-1}$ and $8.5 \mathrm{ng} \mathrm{mL}^{-1}$, respectively. The repeatability and reproducibility of the proposed method were verified by five replicates at $150 \mathrm{ng} \mathrm{mL}^{-1} \mathrm{DOC}$ at same day and two consecutive days [9], and were $97.52 \pm 3.74 \%$ for repeatability (intra-day) and $95.60 \pm 4.15 \%$ reproducibility (inter-day). These results show high accuracy and reliability of the suggested method.

Table 3. Figures of merit for determination of DOC.

\begin{tabular}{|l|l|}
\hline Quantitative analysis & Values \\
\hline Sample volume $(\mathrm{mL})$ & 10 \\
\hline Extraction solvent $(\mu \mathrm{L})$ & 150 \\
\hline Linear range $\left(\mathrm{ng} \mathrm{mL}^{-1}\right)$ & $10.0-400.0$ \\
\hline Coefficient of determination $\left(\mathrm{R}^{2}\right)$ & 0.983 \\
\hline Limit of detections (LOD) $\left(\mathrm{ng} \mathrm{mL}^{-1}\right)$ & 3.6 \\
\hline limit of quantification (LOQ) $\left(\mathrm{ng} \mathrm{mL}^{-1}\right)$ & 8.5 \\
\hline Enrichment factors (EF) & 83.61 \\
\hline Pre-concentration factor (PF) & 66.67 \\
\hline Repeatability (ER $\pm \mathrm{RSD}, \%)$ & $97.52 \pm 3.74 \%$ \\
\hline
\end{tabular}




\begin{tabular}{|l|l|}
\hline Quantitative analysis & Values \\
\hline Reproducibility (ER \pm RSD, \%) & $95.60 \pm 4.15 \%$ \\
\hline
\end{tabular}

\subsection{Analysis of real sample}

The applicability of the proposed method for the recovery of DOC in the biological sample spiked with known amount of DOC was examined. The accumulated urine samples were centrifuged at $4000 \mathrm{rpm}$ for $30 \mathrm{~min}$, filtered through $0.45 \mu \mathrm{m}$ membrane filters and stored at $4^{\circ} \mathrm{C}$ until subsequent application. Also, $5 \mathrm{~mL}$ of the blood sample was poured into centrifuge tubes containing sodium citrate $(4 \% \mathrm{w} / \mathrm{v})$, then the mixture was placed into a centrifuge for $10 \mathrm{~min}$ at $4000 \mathrm{rpm}$. Finally, the supernatant transparent solution or plasma blood was separated, diluted to $10 \mathrm{~mL}$ and used for the next analyses.

An ultrasonication-assisted digestion method was used to treat bovine milk samples. First, $100 \mu \mathrm{L}$ of hydrogen peroxide was added to $30 \mathrm{~mL}$ of milk sample, then sonicated for $15 \mathrm{~min}$. Then, $5 \mathrm{~mL}$ of hydrochloric acid and $5 \mathrm{~mL}$ of acetic acid was added into the above solution and sonicated for $10 \mathrm{~min}$. After that, the final mixture was centrifuged at $5000 \mathrm{rpm}$ for $15 \mathrm{~min}$, and finally, the supernatant was collected and filtered using a cellulose membrane with pore size of $0.22 \mu \mathrm{m}$ and diluted to $50 \mathrm{~mL}$ ultra-pure water. Next, $10 \mathrm{~mL}$ of this diluted solution was utilized for the extraction process [29], and this entire process was replicated 5 times.

The accuracy of the method was verified by spiking known content of analyte and calculating their relative recovery (RR\%), which is listed in Table 4. As seen, DOC is not detected in all biological samples. Regarding the known content addition, the DOC is quantified with recoveries in the interval of $86.7 \%-97.5 \%$, which confirms the successful application of the present approach for real sample and analysis with RSD $<5.7 \%$.

Table 4. Spiked recoveries (\%) of urine, blood plasma and milk samples at optimum conditions.

\begin{tabular}{|c|c|c|c|}
\hline Samples & DOC Added (ng mL ${ }^{-1}$ ) & DOC Found (ng $\mathrm{mL}^{-1}$ ) & RR\% \pm RSD (\%) \\
\hline \multirow[t]{4}{*}{ Urine 1} & 0.0 & N.D* & \\
\hline & 10 & 9.441 & $94.41 \pm 2.80$ \\
\hline & 100 & 97.48 & $97.48 \pm 3.17$ \\
\hline & 250 & 240.63 & $96.25 \pm 3.57$ \\
\hline \multirow[t]{4}{*}{ Urine 2} & 0.0 & N.D* & \\
\hline & 10 & 9.28 & $92.80 \pm 4.31$ \\
\hline & 100 & 95.51 & $95.51 \pm 3.85$ \\
\hline & 250 & 236.4 & $94.56 \pm 3.44$ \\
\hline \multirow[t]{4}{*}{ Urine 3} & 0.0 & N.D* & \\
\hline & 10 & 9.501 & $95.01 \pm 1.63$ \\
\hline & 100 & 96.22 & $96.22 \pm 2.26$ \\
\hline & 250 & 235.73 & $94.29 \pm 2.41$ \\
\hline \multirow[t]{4}{*}{ Urine 4} & 0.0 & N.D* & \\
\hline & 10 & 8.816 & $88.16 \pm 5.28$ \\
\hline & 100 & 91.45 & $91.45 \pm 4.69$ \\
\hline & 250 & 234.88 & $93.95 \pm 5.72$ \\
\hline \multirow[t]{4}{*}{ Urine 5} & 0.0 & N.D* & \\
\hline & 10 & 9.463 & $94.63 \pm 2.94$ \\
\hline & 100 & 95.71 & $95.71 \pm 3.75$ \\
\hline & 250 & 236.33 & $94.53 \pm 3.35$ \\
\hline \multirow[t]{2}{*}{ Blood Plasma 1} & 0.0 & N.D* & \\
\hline & 10 & 9.376 & $93.76 \pm 1.89$ \\
\hline
\end{tabular}




\begin{tabular}{|c|c|c|c|}
\hline & 100 & 92.2 & $92.20 \pm 4.55$ \\
\hline & 250 & 239.91 & $95.96 \pm 4.30$ \\
\hline \multirow[t]{4}{*}{ Blood Plasma 2} & 0.0 & N.D* & \\
\hline & 10 & 8.85 & $88.51 \pm 3.50$ \\
\hline & 100 & 90.62 & $90.62 \pm 3.08$ \\
\hline & 250 & 224.86 & $89.94 \pm 2.96$ \\
\hline \multirow[t]{4}{*}{ Blood Plasma 3} & 0.0 & 9.59 & \\
\hline & 10 & 18.52 & $89.30 \pm 3.85$ \\
\hline & 100 & 101.09 & $91.50 \pm 4.91$ \\
\hline & 250 & 235.71 & $90.45 \pm 3.55$ \\
\hline \multirow[t]{4}{*}{ Blood Plasma 4} & 0.0 & 8.85 & \\
\hline & 10 & 17.94 & $90.90 \pm 2.13$ \\
\hline & 100 & 102.57 & $93.72 \pm 2.49$ \\
\hline & 250 & 244.6 & $94.30 \pm 3.27$ \\
\hline \multirow[t]{4}{*}{ Blood Plasma 5} & 0.0 & N.D* & \\
\hline & 10 & 9.19 & $91.90 \pm 3.16$ \\
\hline & 100 & 93.05 & $93.05 \pm 4.81$ \\
\hline & 250 & 224.9 & $89.96 \pm 3.64$ \\
\hline \multirow[t]{4}{*}{ Milk 1} & 0 & 20.53 & \\
\hline & 10 & 29.5 & $89.70 \pm 4.77$ \\
\hline & 100 & 110.82 & $90.29 \pm 5.39$ \\
\hline & 250 & 254.39 & $93.54 \pm 4.50$ \\
\hline \multirow[t]{4}{*}{ Milk 2} & 0 & 27.7 & \\
\hline & 10 & 36.51 & $88.10 \pm 4.63$ \\
\hline & 100 & 119.28 & $91.58 \pm 5.42$ \\
\hline & 250 & 249.78 & $88.83 \pm 5.11$ \\
\hline \multirow[t]{4}{*}{ Milk 3} & 0 & 14.2 & \\
\hline & 10 & 22.95 & $87.50 \pm 3.19$ \\
\hline & 100 & 104.33 & $90.13 \pm 3.80$ \\
\hline & 250 & 237.31 & $89.24 \pm 3.65$ \\
\hline \multirow[t]{4}{*}{ Milk 4} & 0 & 18.13 & \\
\hline & 10 & 27.44 & $93.10 \pm 4.05$ \\
\hline & 100 & 112.62 & $94.49 \pm 4.30$ \\
\hline & 250 & 247.37 & $91.70 \pm 4.74$ \\
\hline \multirow[t]{4}{*}{ Milk 5} & 0 & 12.95 & \\
\hline & 10 & 22.16 & $92.10 \pm 4.27$ \\
\hline & 100 & 102.09 & $89.14 \pm 3.91$ \\
\hline & 250 & 229.71 & $86.70 \pm 3.52$ \\
\hline
\end{tabular}

$*$ Not detected.

\subsection{Comparison with other studies}

In comparison with other DOC extraction approaches (Table 5), the suggested method requires a lower volume of hazardous solvent owing to the fact that DES can be produced from non-toxic and ecofriendly reagents. As shown in Table 5, the suggested VA-HDES-ferrofluid-DLLME method supplies good analytical efficiency for DOC extraction with lower LOD, in comparison to other studies. Also, this technique offers highly recommended DOC extraction because of its simple pre-concentration process, application nontoxic DES as an extraction solvent and low cost. The analytical efficiency demonstrates that VA-HDES-ferrofluid-DLLME technique consists of an 
effective DOC extraction method in urine, blood plasma and milk samples. The DOC can be measured with the suggested technique at $\mathrm{ng} \mathrm{mL}^{-1}$ levels in intricate sample matrices.

Table 5. Comparison of different methods for determination of DOC with proposed method.

\begin{tabular}{|l|l|l|l|l|}
\hline Extraction Method & Linear Range $\left.\mathbf{( n g} \mathbf{~ m L}^{-\mathbf{1}}\right)$ & $\left.\mathbf{L O D} \mathbf{( n g} \mathbf{~} \mathbf{L}^{\mathbf{- 1}}\right)$ & $\mathbf{R S D} \mathbf{( \% )}$ & Ref. \\
\hline Precipitation & $100-1000$ & 87 & 6.65 & {$[30]$} \\
\hline SPE & $50-500$ & 24.9 & 6.2 & {$[31]$} \\
\hline SPE & $5-1000$ & 0.0508 & $<11.5$ & {$[32]$} \\
\hline MSPE-DLLME & $10.0-200.0$ & $1.8-2.9$ & $<8.8 \%$ & {$[33]$} \\
\hline MEPS & $15-110$ & $0.03-0.21$ & $19 \%$ & {$[34]$} \\
\hline MIP-SPE & $5.0-500$ & 1.17 & $<3.8$ & {$[35]$} \\
\hline VA-HDES-ferrofluid-DLLME & $10-400$ & 3.6 & $<5.8$ & This study \\
\hline
\end{tabular}

\section{Conclusion}

A hydrophobic deep eutectic solvent based on ferrofluid was synthesized and applied for VA-HDES-ferrofluidDLLME and subsequent determination of DOC prior to HPLC-UV. The ferrofluid as green compound was comfortably made from the mixture of magnetic nanoparticles and a hydrophobic deep eutectic solvent. This solvent acted as a carrier liquid to hinder nanoparticles from accumulating by offering shielding layer on all sides of magnetic nanoparticles, consequently enhancing the ferrofluid stability. Unlike most green solvents with hydrophilic features, this solvent not soluble in water. Due to hydrophobic substance of DOC, the hydrophobic interactions between DOC substance and the DES phase in ferrofluid likely act as the main driving force for DOC molecular extraction. Also, vortex-assisted improves the dispersion of the ferrofluid in solution and increases the process of DOC mass transfer to the surface of the ferrofluid, which as a result, propels to higher percentage of DOC extraction in short time.

Meanwhile, several important parameters - such as $\mathrm{pH}$ (3), ionic strength (4\%w/v of $\mathrm{NaCl}$ concentration), $150 \mu \mathrm{L}$ ferrofluid and 7 min vortex-were optimized using CCD. Under optimum conditions, the limit of detection and quantitative is 3.6 and $8.5 \mathrm{ng} \mathrm{mL}^{-1}$, respectively. The DOC extraction percentage in urine and blood plasma samples are between $\mathbf{8 6 . 7 0 \%}$ and $97.48 \%$. The enrichment factor and pre-concentration factor of 83.61 and 66.67 are achieved, respectively. The suitable closeness of pre-concentration factor to enrichment factor acknowledges the quantitatively of the suggested extraction technique. The novel VA-HDES-ferrofluid-DLLME method is rapid, simple, eco-friendly and highly efficient for the DOC extraction in real biological samples.

\section{CRediT authorship contribution statement}

Ebrahim Alipanahpour Dil: Conceptualization, Investigation, Formal analysis, Writing - original draft. Mehrorang Ghaedi: Supervision, Conceptualization, Writing - review \& editing. Arash Asfaram: Investigation, Formal analysis. Lobat Tayebi: Writing - review \& editing. Fatemeh Mehrabi: Writing - original draft.

\section{Declaration of Competing Interest}

The authors declare that they have no conflict of interest.

\section{Acknowledgment}

The authors express their appreciation to the Graduate School and Research Council of the Yasouj University for supporting this work. 


\section{References}

[1] W. Huang, Q. Qiu, M. Chen, J. Shi, X. Huang, Q. Kong, D. Long, Z. Chen, S. Yan. Determination of 18 antibiotics in urine using LC-QqQ-MS/MS. J. Chromatogr. B, 1105 (2019), p. 176

[2] J. Tashkhourian, G. Absalan, M. Jafari, S. Zare. A rapid and sensitive assay for determination of doxycycline using thioglycolic acid-capped cadmium telluride quantum dots. Spectrochim. Acta Part A Mol. Biomol. Spectrosc., 152 (2016), p. 119

[3] Z. Xu, X. Jiang, S. Liu, M. Yang. Sensitive and selective molecularly imprinted electrochemical sensor based on multi-walled carbon nanotubes for doxycycline hyclate determination. Chin. Chem. Lett. (2019), 10.1016/j.cclet.2019.04.026 In Press;

[4] X. Feng, J. Ashley, T. Zhou, Y. Sun. Fluorometric determination of doxycycline based on the use of carbon quantum dots incorporated into a molecularly imprinted polymer. Microchim. Acta, 185 (2018), p. 500

[5] M. Zhu, H. Zhao, D. Xia, J. Du, H. Xie, J. Chen. Determination of 21 antibiotics in sea cucumber using accelerated solvent extraction with in-cell clean-up coupled to ultra-performance liquid chromatography-tandem mass spectrometry. Food Chem., 258 (2018), p. 87

[6] F. Deng, H. Yu, X. Pan, G. Hu, Q. Wang, R. Peng, L. Tan, Z. Yang. Ultra-high performance liquid chromatography tandem mass spectrometry for the determination of five glycopeptide antibiotics in food and biological samples using solid-phase extraction. J. Chromatogr. A, 1538 (2018), p. 54

[7]S.K. Saxena, R. Rangasamy, A.A. Krishnan, D.P. Singh, S.P. Uke, P.K. Malekadi, A.S. Sengar, D.P. Mohamed, A. Gupta. Simultaneous determination of multi-residue and multi-class antibiotics in aquaculture shrimps by UPLC-MS/MS. Food Chem., 260 (2018), p. 336

[8] A.N.M. Nasir, N. Yahaya, N.N.M. Zain, V. Lim, S. Kamaruzaman, B. Saad, N. Nishiyama, N. Yoshida, Y. Hirota. Thiol-functionalized magnetic carbon nanotubes for magnetic micro-solid phase extraction of sulfonamide antibiotics from milks and commercial chicken meat products. Food Chem., 276 (2019), p. 458

[9] M. Tuzen. A new robust, deep eutectic-based floating organic droplets microextraction method for determination of lead in a portable syringe system directly couple with FAAS. Talanta, 196 (2019), p. 71

[10]

M.B. Galuch, T.F.S. Magon, R. Silveira, A.E. Nicácio, J.S. Pizzo, E.G. Bonafe, L. Maldaner, O.O. Santos, J.V. Visentainer. Determination of acrylamide in brewed coffee by dispersive liquid-liquid microextraction (DLLME) and ultra-performance liquid chromatography tandem mass spectrometry (UPLC-MS/MS). Food Chem., 282 (2019), p. 120

[11] D. Yang, X. Li, D. Meng, Y. Yang. Carbon quantum dots-modified ferrofluid for dispersive solid-phase extraction of phenolic compounds in water and milk samples. J. Mol. Liq., 261 (2018), p. 155

[12] P. Zohrabi, M. Shamsipur, M. Hashemi, B. Hashemi. Liquid-phase microextraction of organophosphorus pesticides using supramolecular solvent as a carrier for ferrofluid. Talanta, 160 (2016), p. 340

[13] B. Hashemi, P. Zohrabi, K.-.H. Kim, M. Shamsipur, A. Deep, J. Hong. Recent advances in liquid-phase microextraction techniques for the analysis of environmental pollutants. TrAC Trends Anal. Chem., 97 (2017), p. 83

[14] N.C.C. Lobato, Â. de Mello Ferreira, M.B Mansur. Evaluation of magnetic nanoparticles coated by oleic acid applied to solvent extraction processes. Sep. Purif. Technol., 168 (2016), p. 93

[15] D. Yang, G. Li, L. Wu, Y. Yang. Ferrofluid-based liquid-phase microextraction: Analysis of four phenolic compounds in milks and fruit juices. Food Chem., 261 (2018), p. 96

[16] T.L.S. Coelho, F.M.S. Braga, N.M.C. Silva, C. Dantas, C.A.L. Júnior, S.A.A. de Sousa, E.C. Vieira. Optimization of the protein extraction method of goat meat using factorial design and response surface methodology. Food Chem., 281 (2019), p. 63

[17] M. Heydari, S.M. Ghoreishi, A. Khoobi. Chemometrics-assisted determination of Sudan dyes using zinc oxide nanoparticle-based electrochemical sensor. Food Chem., 283 (2019), p. 68 
[18] E.A. Dil, M. Ghaedi, A. Asfaram, F. Mehrabi, A.A. Bazrafshan, A.M. Ghaedi. Trace determination of safranin $O$ dye using ultrasound assisted dispersive solid-phase micro extraction: Artificial neural networkgenetic algorithm and response surface methodology. Ultrason. Sonochem., 33 (2016), p. 129

[19] E.A. Dil, M. Ghaedi, A. Asfaram, F. Zare, F. Mehrabi, F. Sadeghfar. Comparison between dispersive solidphase and dispersive liquid-liquid microextraction combined with spectrophotometric determination of malachite green in water samples based on ultrasound-assisted and preconcentration under multivariable experimental design optimization. Ultrason. Sonochem., 39 (2017), p. 374

[20] E.A. Dil, M. Ghaedi, A. Asfaram, F. Mehrabi. Application of modificated magnetic nanomaterial for optimization of ultrasound-enhanced removal of $\mathrm{Pb} 2+$ ions from aqueous solution under experimental design: Investigation of kinetic and isotherm. Ultrason. Sonochem., 36 (2017), p. 409

[21] H. Nosrati, N. Sefidi, A. Sharafi, H. Danafar, H.K. Manjili. Bovine serum albumin (BSA) coated iron oxide magnetic nanoparticles as biocompatible carriers for curcumin-anticancer drug. Bioorg. Chem., 76 (2018), p. 501

[22] M. Imran, A.R. Ansari, A.H. Shaik, S. Hussain, A. Khan, M.R. Chandan. Ferrofluid synthesis using oleic acid coated Fe304 nanoparticles dispersed in mineral oil for heat transfer applications. Mater. Res. Exp., 5 (2018), Article 036108

[23] E.A. Dil, M. Ghaedi, A. Asfaram. Application of hydrophobic deep eutectic solvent as the carrier for ferrofluid: A novel strategy for pre-concentration and determination of mefenamic acid in human urine samples by high performance liquid chromatography under experimental design optimization. Talanta, 202 (2019), p. 526

[24] N.N. Marnani, A. Shahbazi. A novel environmental-friendly nanobiocomposite synthesis by EDTA and chitosan functionalized magnetic graphene oxide for high removal of Rhodamine B: Adsorption mechanism and separation property. Chemosphere, 218 (2019), p. 715

[25] A. Asfaram, H. Sadeghi, A. Goudarzi, E. Panahi Kokhdan, Z. Salehpour. Ultrasound combined with manganese-oxide nanoparticles loaded on activated carbon for extraction and pre-concentration of thymol and carvacrol in methanolic extracts of Thymus daenensis, Salvia officinalis, Stachys pilifera, Satureja khuzistanica, and mentha, and water samples. Analyst, 144 (2019), p. 1923

[26] Ç. Arpa, I. Arıdaşır. Ultrasound assisted ion pair based surfactant-enhanced liquid-liquid microextraction with solidification of floating organic drop combined with flame atomic absorption spectrometry for preconcentration and determination of nickel and cobalt ions in vegetable and herb samples. Food Chem., 284 (2019), p. 16

[27] E. Alipanahpour Dil, A. Asfaram, F. Sadeghfar. Magnetic dispersive micro-solid phase extraction with the CuO/ZnO@Fe304-CNTs nanocomposite sorbent for the rapid pre-concentration of chlorogenic acid in the medical extract of plants, food, and water samples. Analyst, 144 (2019), p. 2684

[28] Z. Moradi, E. Alipanahpour Dil, A. Asfaram. Dispersive micro-solid phase extraction based on Fe304@SiO2@Ti-MOF as a magnetic nanocomposite sorbent for the trace analysis of caffeic acid in the medical extracts of plants and water samples prior to HPLC-UV analysis. Analyst, 144 (2019), p. 4351

[29] Y. Yao, H. Wu, J. Ping. Simultaneous determination of Cd (II) and Pb (II) ions in honey and milk samples using a single-walled carbon nanohorns modified screen-printed electrochemical sensor. Food Chem., 274 (2019), p. 8

[30] S.M. Sunarić, M.S. Denić, Z.Ž. Bojanić, V.V. Bojanić. HPLC method development for determination of doxycycline in human seminal fluid. J. Chromatogr. B, 939 (2013), p. 17

[31] P. Moudgil, J.S. Bedi, R.S. Aulakh, J.P.S. Gill, A. Kumar. Validation of HPLC Multi-residue Method for Determination of Fluoroquinolones, Tetracycline, Sulphonamides and Chloramphenicol Residues in Bovine Milk. Food Anal. Methods, 12 (2019), p. 338

[32] Y. Yang, S. Yin, D. Yang, Y. Jiang, Y. Li, C. Zhou, C. Sun. Carboxyl $\mathrm{Fe}_{3} \mathrm{O}_{4}$ magnetic nanoparticle-based SPE and HPLC method for the determination of six tetracyclines in water. Anal. Bioanal. Chem., 411 (2019), p. 507 
[33] N. Al-Afy, H. Sereshti, A. Hijazi, H. Rashidi Nodeh. Determination of three tetracyclines in bovine milk using magnetic solid phase extraction in tandem with dispersive liquid-liquid microextraction coupled with HPLC. J. Chromatogr. B, 1092 (2018), p. 480

[34] E. Vasconcelos Soares Maciel, B. Henrique Fumes, A. Lúcia de Toffoli, F. Mauro Lanças. Graphene particles supported on silica as sorbent for residue analysis of tetracyclines in milk employing microextraction by packed sorbent. Electrophoresis, 39 (2018), p. 2047

[35] Y. Xu, Y. Tang, Y. Zhao, R. Gao, J. Zhang, D. Fu, Z. Li, H. Li, X. Tang. Bifunctional monomer magnetic imprinted nanomaterials for selective separation of tetracyclines directly from milk samples. J. Colloid Interface Sci., 515 (2018), p. 18 